\title{
ESTABELECIMENTO DO CONTROLE DE ESTÍMULOS E DO COMPORTAMENTO DE OBSERVAÇÃO POR DIFERENÇA DE CUSTO DE RESPOSTAS
}

\author{
ESTABLISHING STIMULUS CONTROL AND OBSERVING BEHAVIOR BY \\ DIFFERENCES IN RESPONSE COST
}

\section{Candido Vinicius Bocaiuva Barnsley Pessoa ${ }^{1}$ e Tereza Maria de Azevedo Pires SÉRIO ${ }^{2}$}

PONTIFÍCIA UNIVERSIDADE CATÓLICA DE SÃO PAULO, BRASIL

\begin{abstract}
RESUMO
Definindo-se comportamento de observação como aquele que produz estímulos discriminativos para outro comportamento, foi realizado um experimento em que a principal variável manipulada foi o custo relativo entre as respostas de observação e as do outro comportamento (de produção). Foram registradas as respostas nos dois comportamentos em diferentes esquemas de reforçamento. Seis pessoas adultas foram divididas em dois grupos. Os participantes do Grupo 1 foram primeiro expostos a um esquema múltiplo. Durante os componentes de reforçamento, pressōes em um botão produziam pontos que eram trocados por dinheiro ao final da sessão. Após atingir um índice de discriminação de 0,9 ou mais por três ou mais sessões consecutivas, eles seriam expostos a um esquema misto, com possibilidade de emissão de respostas de observação em outro botão. Os participantes do Grupo 2 foram expostos diretamente a esta segunda condição. Os participantes do Grupo 2 atingiram índices de discriminação maiores que os do Grupo 1, principalmente após o estabelecimento de uma resposta de observação com um custo inferior ao da resposta que produzia pontos. Discute-se a relevância da análise do custo entre as respostas no estabelecimento do comportamento de observação e do controle de estímulos.
\end{abstract}

Palavras-chave: comportamento de observação, resposta de observação, custo de resposta, atenção, controle de estímulos, humanos.

\section{ABSTRACT}

To consider observing behavior as the behavior that produces discriminative stimuli for another behavior, an experiment was conducted in which the main manipulated variable was the relative cost between observing response and the other behavior's response. Frequencies and durations were registered for both responses. Six adult humans were divided into two groups. The first group's participants were exposed to a multiple schedule. Pressing a button during reinforcement components produced points later exchanged for money. After reaching a discrimination index of at least 0.9 for three consecutive sessions, participants were supposed to be exposed to a mixed schedule with an observing response available through another button. The second group's participants were directly exposed to this second condition. The second group's participants achieved higher discrimination index than the first group's mainly after reversing the cost of the responses. The relevance of inter-response cost analysis was discussed to establish relations between observing behavior and stimulus control.

Key words: observing behavior, observing response, cost of response, attention, stimulus control, humans.

"Respostas de observação podem ser definidas como aquelas que resultam na exposição a um par de estímulos discriminativos" (Wyckoff, 1969, p.237). Seu estudo pode ser descrito como o estudo de um comportamento produzindo os estímulos discriminativos para outro comportamento. Esse outro comportamento será chamado aqui de comportamento de produção. Nos experimentos em que o comportamento de observação produz os estímulos antecedentes das contingências programadas para o comportamento de produção, alterando um esquema misto para um esquema múltiplo (por exemplo, Wyckoff, 1969), a ocorrência do comportamento de observação não altera o número de reforçadores programados nas contin-

1 Atualmente vinculado à Universidade de São Paulo. Correspondências: candidopessoa@uol.com.br

2 Artigo elaborado durante vigência de Bolsa Produtividade CNPq da autora. 
gências do comportamento de produção. Desta perspectiva, tais estímulos antecedentes teriam função reforçadora para o comportamento de observação. Uma questão que surge é se a função de estímulo reforçador pode ser exercida pelos dois estímulos discriminativos, tanto o da contingência relativamente menos favorável como o da contingência mais favorável.

Perone e Baron (1980) relataram, dentre três experimentos, dois nos quais foi estudada a função do estímulo relacionado com o menos favorável entre dois componentes ${ }^{3}$ (de extinção ou com maior custo de resposta) para o comportamento de produção. Sete pessoas adultas participaram do primeiro experimento. Elas foram informadas de que seriam pagas pelo número de movimentos de um ponteiro de um mostrador que conseguissem detectar. Os participantes deveriam pressionar uma alavanca para produzir iluminação que tornava possível ver o ponteiro no mostrador. Estas pressões produziam, também, os movimentos do ponteiro (fato não informado aos participantes). Para funcionar, a alavanca deveria ser pressionada com uma força de aproximadamente $22 \mathrm{~N}$. Quando os movimentos do ponteiro ocorriam, os participantes apertavam um botão que registrava a detecção de um movimento e recolocava o ponteiro no lugar inicial. Os movimentos do ponteiro eram contingentes às respostas na alavanca em esquema múltiplo de dois componentes (mult VI EXT): um de intervalo variável 60 segundos (VI 60s) e um de extinção (EXT). Os componentes tinham duração média de cinco minutos e se alternavam aleatoriamente. Depois de estabelecido o controle discriminativo de uma luz (um determinado comprimento de onda) para cada um dos dois componentes para o comportamento de produção, a fase de observação foi iniciada. Nesta fase, para o comportamento de produção (que produzia os movimentos do ponteiro) passou a vigorar um esquema misto VI 60s EXT. Os participantes podiam emitir uma de duas respostas de observação - pressões em dois botóes que exigiam $0,9 \mathrm{~N}$ para serem operados. Essas respostas foram dispostas em esquema concorrente de dois VI 30s independentes (conc VI VI). Uma resposta de observação produzia a luz relacionada ao componente VI (S1) ou a luz relacionada ao componente EXT $(\mathrm{S} 2)^{4}$, conforme o componente para o comportamento de produção. A resposta de observação concorrente (pressão no outro botão) produzia somente o estímulo relacionado ao componente VI (S1). Quando pressionado durante o tempo em que o componente EXT estava em vigor, pressões a este segundo botão não apresentavam conseqüências. Uma vez produzido, o estímulo contingente à resposta de observação permanecia em vigor por 15 segundos. $O$ resultado de maior importância para o presente relato foi que cinco dos sete participantes emitiram mais respostas de observação que produziam S1 e S2 do que respostas de observação que produziam somente S1, ou seja, o comportamento de observação que mais ocorreu foi o que tinha também como conseqüência a produção do estímulo relacionado ao componente menos favorável (extinção).

Três pessoas adultas participaram do segundo experimento. Novamente, a tarefa foi registrar os movimentos dos ponteiros do mostrador. Em relação ao comportamento de produção, alternavam-se aleatoriamente dois componentes de um esquema múltiplo: durante um

$3 \mathrm{Na}$ descrição de esquemas complexos de reforçamento é prática comum substituir a expressão "contingência" pela expressão "componente".

4 Para facilitar a leitura deste texto, procurou-se sempre indicar como S2 o estímulo que estava relacionado ao menos favorável de dois componentes na contingência de produção. 
componente, respostas em duas alavancas podiam produzir movimentos do ponteiro, uma alavanca exigia maior esforço para ser operada $(66 \mathrm{~N})$ e outra menor esforço $(22 \mathrm{~N})$; durante o outro componente, apenas respostas na alavanca de maior esforço produziam movimentos no ponteiro. Uma luz foi relacionada à possibilidade de produção de movimentos nos ponteiros nas duas alavancas (S1) e outra luz à possibilidade de produção de movimentos somente através da alavanca de maior esforço (S2). Após o desempenho discriminado em relação às luzes, iniciou-se a fase de observação. Nesta fase, uma das respostas de observação, também em esquemas concorrentes, produzia S1 e S2 e a outra apenas $\mathrm{S} 1$. Os três participantes emitiram mais as respostas de observação que produziam S1 e S2, ou seja, novamente o comportamento de observação que mais ocorreu foi o que tinha também como conseqüência a produção do estímulo relacionado ao componente menos favorável (maior esforço). Perone e Baron (1980) concluíram que há situações em que o estímulo relacionado ao componente menos favorável para o comportamento de produção também pode ser reforçador para o comportamento de observação.

Case, Fantino e Wixted (1985) realizaram dois experimentos nos quais investigaram possíveis razões para os resultados de Perone e Baron (1980). A hipótese dos autores era que a ocorrência do comportamento de observação que tinha também como conseqüência a produção do estímulo discriminativo do componente menos favorável para o comportamento de produção foi devida à possibilidade de diminuição no custo de respostas no comportamento de produção.

O primeiro experimento de Case e cols. (1985) contou com a participação de dez indi- víduos adultos. Cada indivíduo participou de três sessões. Em todas as sessões, respostas em uma alavanca tinham um custo de $1,2 \mathrm{~N}$ e produziam pontos, acumulados em dois marcadores e trocados por dinheiro no final da sessão. A produção de pontos era contingente a respostas em um esquema misto de dois componentes VI 30s (mix VI VI). Cada componente tinha duração fixa de 60 segundos e os dois se alternavam randomicamente. Durante um componente, responder na alavanca produzia cinco pontos. Durante o outro componente, responder na alavanca produzia apenas um ponto. Duas outras alavancas com o mesmo custo de resposta $(1,2 \mathrm{~N})$ estavam disponíveis. Em esquema concorrente de dois VI 15s independentes (conc VI VI), respostas em cada uma destas outras alavancas produziam uma luz que durava até o fim do componente em vigor para a alavanca que produzia pontos. Porém, essas luzes só eram produzidas em metade dos componentes, aleatoriamente. A função das luzes produzidas pelas respostas nas alavancas variou ao longo de cada uma das três sessões. Essa função era explicitada em instrução fornecida ao participante antes do início da sessão. Na primeira sessão, respostas em uma alavanca produziam luz vermelha (S1) que, segundo as instruções, "informava” que pressões na alavanca de pontos naquele momento produziriam cinco pontos. Respostas na outra alavanca produziam luz azul (S2) que "informava” que pressões na alavanca de pontos, naquele momento, produziriam um ponto. $\mathrm{Na}$ segunda sessão, respostas em uma alavanca produziam luz vermelha (S1), que "informava” que pressões na alavanca de pontos produziriam, naquele momento, cinco pontos. Respostas na outra alavanca produziam luz azul (estímulo não relacionado especificamente a nenhum dos dois com- 
ponentes do mix VI VI-SU) que "informava” que durante metade do tempo pressões na alavanca de pontos produziriam cinco pontos e, na outra metade, produziriam um ponto. $\mathrm{Na}$ terceira sessão, respostas em uma alavanca produziam luz azul (S2) que "informava" que respostas na alavanca de pontos produziriam um ponto. Respostas na outra alavanca de observação produziam luz vermelha (SU) que "informava" que durante metade do tempo pressões na alavanca de pontos produziriam cinco pontos e na outra metade produziriam um ponto. $\mathrm{Na}$ segunda e terceira sessões, respostas em somente uma das duas alavancas transformavam o esquema misto em esquema múltiplo. Pressões na alavanca que produzia SU faziam com que os participantes permanecessem sob esquema misto. Nas instruções, estava explícito que a produção de luzes não alterava a possibilidade de ganho de pontos, apenas as sinalizava. Essa compreensão das instruções foi verificada em questionário que os participantes responderam. Os dez participantes experimentaram as três sessões em ordens diferentes.

Os pesquisadores relataram a média das freqüências de respostas emitidas pelos dez participantes em cada alavanca que produzia luz. $\mathrm{Na}$ sessão em que os participantes foram expostos à escolha entre produção de $S 1$ ou produção de S2, os participantes produziram S1 em $76 \%$ dos componentes. Na comparação entre produção de $\mathrm{S} 1$ e produção de $\mathrm{SU}, \mathrm{S} 1$ foi produzido em $66 \%$ dos componentes e na comparação entre produção de S2 e produção de SU, SU foi produzido em 75\% dos componentes. Na primeira sessão, o comportamento de observação de maior ocorrência foi o que tinha como conseqüência a produção do estímulo relacionado ao componente mais favorável (S1 em relação a S2); na segunda ses- são, ocorreu mais o comportamento de observação que tinha como conseqüência o $S 1$, em relação a permanecer em esquema misto (produzir SU); na terceira sessão, ocorreu mais a permanência em esquema misto (emissão de SU) do que o comportamento de observação que produzia apenas o estímulo relacionado ao menos favorável dos dois componentes.

Seis indivíduos adultos participaram do segundo experimento, por três sessões cada um. A produção de pontos passou a ocorrer contingente a respostas em uma alavanca cujo esforço para operação era de $22 \mathrm{~N}$. A antiga alavanca de produção de pontos passou a servir para emissão de uma resposta chamada pelos autores de consumatória - quando pontos eram disponibilizados pela emissão de respostas na alavanca de produção de pontos, uma luz verde acendia sobre a alavanca de resposta consumatória que, então, deveria ser pressionada para que os pontos fossem somados em um contador. $\mathrm{O}$ esforço necessário para operação da alavanca de resposta consumatória e das alavancas que podiam produzir luzes permaneceu em 1,2 N. As contingências programadas para respostas na alavanca de produção de pontos mudaram ao longo das sessões. Na primeira sessão vigorou um esquema misto intervalo variável extinção (mix VI EXT); na segunda sessão vigorou um esquema misto tempo variável extinção (mix VT EXT). Neste segundo esquema, não era necessária emissão de respostas na alavanca de pontos para o participante receber pontos, apenas a emissão da resposta consumatória era necessária. Na terceira sessão, voltou a vigorar o esquema mix VI EXT. Para três dos seis participantes a ordem das sessões foi inversa. Durante todas as sessões, respostas em uma alavanca produziam apenas a luz relacionada à EXT (S2), quando este componente 
estivesse em vigor, e respostas na outra alavanca produziam apenas um estímulo não relacionado com os componentes do esquema (SU) por metade do tempo. Como no experimento anterior, as relações entre luzes e alavanca de produção de pontos foram explicitadas em instruções lidas aos participantes e questionários aplicados verificavam a compreensão das instruções.

Como resultado deste segundo experimento tem-se que, nas sessões de mix/mult VI EXT, a produção de $\mathrm{S} 2$ foi o dobro da produção de SU, ou seja, o estímulo relacionado com o componente menos favorável (EXT) reforçou o comportamento de observação. Quando o esquema de recebimento de pontos era mix/mult VT EXT e, portanto, não exigia pressões na alavanca de pontos, a produção de S2 foi metade da produção de SU, ou seja, os participantes emitiram respostas que os faziam permanecer em um esquema misto.

Case e cols. (1985) concluíram que os resultados de seus dois experimentos e os de Perone e Baron (1980) indicam que o comportamento de observação pode ser mantido pela produção de estímulos relacionados ao componente menos favorável, quando há possibilidade de diminuição no custo de emissão de respostas no comportamento de produção.

Os experimentos relatados até aqui analisaram o comportamento de observação em situações de esquemas concorrentes. Um dos poucos experimentos que investigou o comportamento de observação com humanos em uma situação de operante livre tanto na observação quanto na produção foi realizado por Mulvaney, Hughes, Jwaideh e Dinsmoor (1981). Estes pesquisadores analisaram o comportamento de observação de três crianças. As respostas de observação alteravam um esquema misto VI EXT para um esquema múltiplo VI EXT, ao produ- zir sucessivamente S1 ou S2. Os estímulos S1 e S2 permaneciam presentes pelo tempo em que a resposta de observação fosse emitida e de acordo com a vigência dos componentes para o comportamento de produção. Primeiramente, foi estabelecido controle discriminativo, no esquema múltiplo VI 20s EXT, do comportamento de produção. Durante a vigência do componente VI, que se alternava com o componente EXT de forma randômica, pressões num botão produziam moedas que caiam de um dispensador. Com o estabelecimento do controle discriminativo, as crianças passaram a pressionar o botão de produção apenas na presença da luz relacionada ao componente VI (S1). Numa segunda fase, as crianças foram expostas à condição em que a produção dos estímulos discriminativos para o comportamento de produção dependia de emissão das respostas de observação - pressões a um segundo botão que produziam, pelo tempo em que o botão permanecesse pressionado, S1 ou S2, conforme o componente em vigor para o comportamento de produção. Ao analisar o comportamento de observação, Mulvaney e cols. (1981) descreveram as respostas de observação que produziam S1 como mais longas do que as respostas de observação que produziam S2. Para um participante, as respostas que produziram S2 foram mais freqüentes que as respostas que produziram S1. Essas características do comportamento de observação foram denominadas por Dinsmoor (1983) de observação seletiva. Na observação seletiva, ao emitir-se uma resposta de observação, se for produzido $S 1$, a duração da resposta de observação tende a ser mais longa do que quando é produzido S2. Já a freqüência das respostas que produzem S2 tende a ser maior do que as que produzem S1 (Dinsmoor, 1983). 
No presente experimento, inicialmente tentou-se uma replicação sistemática do procedimento de Mulvaney e cols. (1981) para investigar, em pessoas adultas, a observação seletiva em situaçôes com e sem o treino de discriminação antes da fase de observação. Devido a dificuldades no estabelecimento de controle por estímulos do comportamento de produção, incorporaram-se ao presente método os achados já relatados (Chase \& cols., 1985; Perone \& Baron, 1980) relativos ao efeito do custo da resposta no comportamento de produção no estabelecimento do comportamento de observação. Com isso, o custo relativo entre as respostas do comportamento de observação e as respostas do comportamento de produção foi manipulado. Procurou-se, assim, verificar o efeito da inversão do custo relativo das respostas de produção e de observação, em uma situação de operante livre, na ocorrência de respostas de observação.

\section{MÉTODO}

\section{Participantes}

Seis pessoas, com idades entre 22 e 42 anos serviram como participantes deste experimento. Os participantes foram recrutados entre trabalhadores de uma empresa de limpeza que presta serviços a uma universidade privada da cidade de São Paulo. Foi dito a eles que durante a tarefa eles receberiam pontos que poderiam ser trocados por dinheiro e que ao completarem as cinqüenta sessões programadas para o experimento receberiam ressarcimento de cem reais pelo tempo despendido. A soma do dinheiro recebido como ressarcimento e pela troca de pontos provavelmente representou soma relevante em comparação com o salário mensal de cada um. Os dados foram coletados após a leitura conjunta e assinatura de um termo de consentimento esclarecido.

\section{Ambiente experimental e equipamento}

$\mathrm{O}$ ambiente experimental foi uma pequena sala do Laboratório de Psicologia Experimental da universidade. A sala tinha uma porta, uma cadeira e o aparato descrito a seguir. Um computador localizado na sala ao lado, controlou o aparato e realizou os registros de respostas. Uma câmera de vídeo foi utilizada para gravação das primeiras 37 sessôes de um dos participantes (P5) e das primeiras 32 sessóes de outro (P6). Após este período, foi encerrada a observação direta por esta não produzir dados relevantes sobre o desempenho nos comportamentos analisados no presente experimento.

Um aparato foi construído para o experimento (Figura 1). Em uma caixa de madeira forrada por fórmica branca de 66 centímetros de altura, 46 centímetros de largura e 9 centímetros de espessura havia dois botóes quadrados de quatro centímetros de lado cada um. Estes botôes estavam centralizados e dispostos um acima do outro. Os botóes podiam ser iluminados de vermelho, azul ou ficar sem iluminação, quando tinham cor branca. Pressôes nestes botóes necessitavam de aproximadamente 1,8 $\mathrm{N}$ de força para terem efeito. Acima dos botôes, havia um alto-falante que, durante as sessões, emitia um breve som de moedas caindo quando os participantes recebiam pontos. Do lado esquerdo do alto-falante havia um contador que mostrava os pontos acumulados pelo participante durante uma sessão e, do lado direito do alto-falante, havia uma lâmpada com luz branca que ficava acesa durante a sessão experimental. $\mathrm{O}$ aparato foi fixado na parede com a parte inferior distante 82 centímetros do solo, de maneira que o botão inferior ficasse aproxi- 
madamente na altura dos olhos de uma pessoa de um metro e sessenta e cinco centímetros de altura que estivesse sentada na sua frente.

Um programa de computador foi elaborado em Visualbasic $\AA$ para controlar a apresentação de pontos, o som e a iluminação dos botôes, assim como efetuar o registro de freqüência e duração das respostas dadas em cada botão.

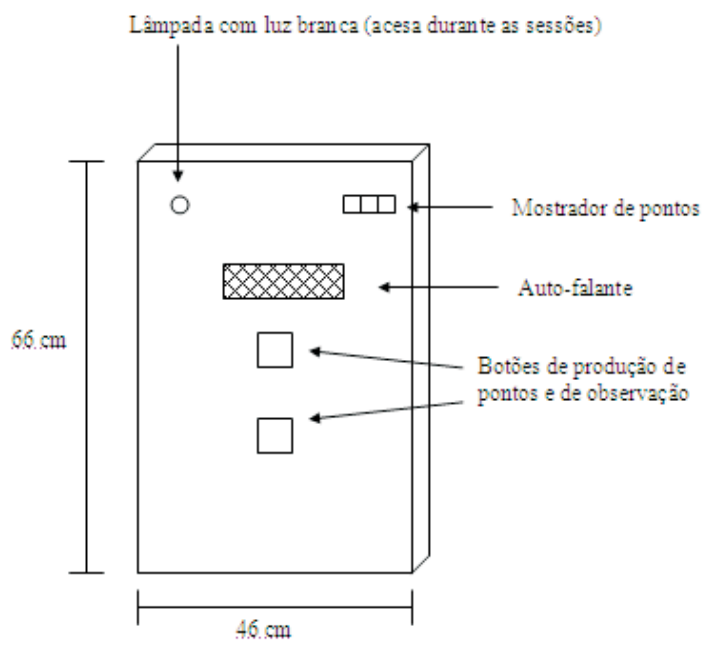

Figura 1. Representação do aparato utilizado no experimento.

\section{Procedimento}

Cada participante realizou cinqüenta sessões individuais de aproximadamente vinte minutos de duração cada uma. As sessões eram realizadas de segunda a sexta-feira e cada participante realizava duas sessões por dia. A cada sessão, os participantes eram expostos a um esquema múltiplo ou misto composto por dois componentes: um de reforçamento em intervalo, no qual o participante poderia ganhar pontos, e um de extinção. A duração de cada componente era, em média, 90 segundos, podendo variar entre 10 e 180 segundos. O método para estabelecimento das diferentes durações de cada componente e das duraçôes dos intervalos nos componentes de reforçamento foi descrito de forma detalhada por Pessôa e Buffara (2005). Pela impossibilidade que o equipamento tinha em realizar reforçamento de cada resposta emitida pelo participante (esquema de reforçamento contínuo ou CRF) devido à alta freqüência de respostas emitidas, um componente de intervalo fixo 0,62 segundo foi utilizado como aproximação de um CRF.

Após a segunda sessão do dia, os pontos recebidos durante as duas sessões daquele dia eram trocados por dinheiro. $\mathrm{O}$ recebimento de pontos foi programado de forma que os participantes pudessem receber sempre o máximo de três reais por sessão. Por essa razão, pontos valeram $\mathrm{R} \$ 0,01$ em VI 20s, R\$ 0,005 em VI 10s, R\$ 0,003 em VI 6,6s e R\$ 0,00035 em FI 0,62s. Durante as sessões com VI 20s, com VI 10s e com VI 6,6s, cada reforçamento era realizado com a apresentação de 10 pontos e durante as sessões com FI 0,62s cada reforçamento era realizado com a apresentação de 1 ponto.

Antes da primeira sessão, os participantes receberam as seguintes instruções, lidas em voz alta pelo experimentador:

Durante a sessão você pode ganhar pontos que serão trocados por um centavo cada um no final da sessão. Os pontos são somados aqui (o experimentador aponta para o contador de pontos). Você ouvirá um som que indica o momento em que você está ganhando pontos. A luz branca no mostrador do painel indica o começo e o fim da sessão.

Esta é uma tarefa bem simples. Tudo o que você tem que fazer é apertar aqueles botões. Não adianta apertá-los o tempo todo para ganhar o máximo possível de pontos.

Como as instruções não ficaram disponíveis para os participantes o tempo todo e devi- 
do ao baixo controle que as luzes estavam exercendo sobre as respostas de produção, as instruções foram reapresentadas antes da Sessão 17, para $\mathrm{P} 5$ e P6, antes da Sessão 23, para P7, e antes da Sessão 21, para P8. Em nenhum momento houve avaliação da compreensão das instruçôes ou questionamento sobre elas pelos participantes.

Para se avaliar os efeitos do treino de discriminação sobre a aquisição do comportamento de observação, os seis participantes foram divididos em dois grupos de três pessoas cada um. Estes grupos foram denominados G1 e G2. A principal diferença entre estes dois grupos foi que os participantes do G1 foram expostos primeiro a esquemas múltiplos e os participantes do G2 foram expostos diretamente a esquemas mistos e podiam emitir respostas de observação, que geravam os estímulos relacionados a cada componente. A coleta de dados foi realizada com dois participantes de cada vez (em sessões individuais seguidas), sempre um do G1

\section{Tabela 1}

Contingência em vigor no componente de reforçamento do esquema múltiplo, por sessão, de cada participante do Grupo 1.

\begin{tabular}{ccc}
\hline Participante & Sessōes & $\begin{array}{c}\text { Componente } \\
\text { de ref. }\end{array}$ \\
\hline P5 & 1 a 50 & VI 20s \\
P7 & 1 a 22 & VI 6,6s \\
& 23 a 39 & FI $0,62 \mathrm{~s}$ \\
& 40 a 50 & FI $0,62 \mathrm{~s}(\mathrm{mix})^{*}$ \\
P9 & 1 a 10 & FI $0,62 \mathrm{~s}$ \\
& 11 a 35 & VI $6,6 \mathrm{~s}$ \\
& 36 a 45 & VI $10 \mathrm{~s}$ \\
& 46 a 48 e 54 & VI $20 \mathrm{~s}$ \\
49 a 53 & VI 20s (mix)*
\end{tabular}

* Nas exceções em que o esquema era misto, o BO estava disponível. e um do G2. As sessões de cada par de participantes só começaram após o fim das sessões do par anterior. As tabelas 1 e 2 apresentam a seqüência de esquemas e valores de intervalo a que os participantes do G1 e do G2 foram respectivamente expostos.

Para os participantes do G1 (P5, P7 e P9), após o início da sessão, quando pressionado, o botão inferior do equipamento à sua frente (Botão de Produção de Pontos ou BPP) produzia pontos segundo um esquema mult VI EXT. Durante a vigência do componente VI, o BPP era iluminado de vermelho, e, durante o componente de EXT, o BPP era iluminado de azul. Para P5, o botão superior (que seria, na vigência de um esquema misto, o Botão de Observação ou $\mathrm{BO}$ ) ficou disponível para respostas e era iluminado simultaneamente ao BPP, mas não havia contingências programadas para ele. Para P7 e P9 o segundo botão foi tampado. A partir da Sessão 31, para P7, e em todas as ses-

Tabela 2

Contingência em vigor no componente de reforçamento do esquema misto durante o qual o BO estava disponível, por sessão, de cada participante do Grupo 2. Não houve conseqüências programadas para $\mathrm{BO}$ nas sessóes 43 a 49 de P8 e nas Sessōes 48 e 49 de P10.

\begin{tabular}{ccc}
\hline Participante & Sessões & $\begin{array}{c}\text { Componente } \\
\text { de ref. }\end{array}$ \\
\hline P6 & 1 a 50 & VI 20s \\
& 1 a 20 & VI 6,6s \\
P8 & 21 a 50 & VI 20s \\
& 1 a 5 & FI 0,62s \\
P10 & 6 a 18 & VI 6,6s \\
& 19 a 24 & VI $10 s$ \\
& 25 a 50 & VI 20s \\
\hline
\end{tabular}


sôes, para P9, a posição dos botôes foi invertida, passando o botão de cima a ser o BPP e o de baixo a ser o botão tampado ou o BO.

Ao atingirem o índice de discriminação (respostas no BPP durante componente com reforçamento dividido pelo total de respostas no BPP) de $90 \%$ por três ou mais sessões, os participantes deveriam ser expostos a um esquema mix VI EXT (os dois botóes permaneciam sem iluminação), que podia ser alterado para o esquema múltiplo pelo tempo que o $\mathrm{BO}$ permanecesse pressionado. Caso o componente mudasse durante uma resposta no $\mathrm{BO}$, a luz que iluminava os botóes mudava de acordo com o novo componente. Porém, nenhum participante deste grupo atingiu o índice estabelecido como critério para mudança. Mesmo assim, P7 foi exposto ao esquema misto, da sessão 39 até a sessão 50, e P9, da sessão 49 à sessão 53, independentemente dos índices de discriminação apresentados até então. P9 ainda voltou à situação de esquema mult VI 20s EXT por uma sessão (sessão 54). P5, apesar de não atingir o critério estabelecido, apresentou um índice de discriminação crescente por todo o experimento, permanecendo, assim, no esquema múltiplo.

Os participantes do G2 (P6, P8 e P10) foram expostos diretamente a esquemas mistos de recebimento de pontos com o BPP na posição inferior. Os esquemas mistos podiam ser transformados em múltiplos pelo tempo que durassem as respostas no botão de cima (BO). Quando em vigor o esquema múltiplo, as mesmas luzes usadas para o G1 foram relacionadas aos componentes em vigor para produção de pontos (vermelho para os componentes em que havia reforçamento programado e azul para os componentes em que não havia reforçamento programado). Após a sessão 31, para P8, e durante todas as sessões, para $\mathrm{P} 10$, a posição dos botões foi invertida (o BPP passou a ser o superior e o $\mathrm{BO}$ passou a ser o inferior). Ao atingirem um índice de discriminação no responder no BPP de $90 \%$ ou mais por pelo menos três sessões, os participantes deste grupo foram expostos a uma situação de extinção da resposta de observação, ou seja, respostas no BO não tinham conseqüência programada e, portanto, não transformavam mais o esquema misto em esquema múltiplo. Para ambos os grupos não houve restrição a pressões simultâneas nos botôes.

\section{RESULTADOS}

As respostas emitidas no botão de produção de pontos por todos os participantes permitiram que cada um ganhasse quase a totalidade dos pontos disponíveis em cada sessão: P5 ganhou 92\% dos pontos disponíveis em toda sua participação no experimento, P6 ganhou 91\%, P7 ganhou 86\%, P8 ganhou 97\%, P9 ganhou 93\% e P10 ganhou 94\%. Nenhum participante ganhou menos de 75\% dos pontos disponíveis por mais de duas sessões. Não foi notada nenhuma alteração no comportamento de pressão do BPP ou BO relacionada às mudanças no valor dos pontos ou à apresentação de um em um ou de dez em dez pontos por reforço.

Para cada sessão de cada participante, um índice de discriminação das respostas de pressão à barra em relação ao controle exercido pelas luzes vermelha e azul foi calculado. Este índice é a proporção das respostas emitidas no BPP durante os componentes de reforçamento em relação ao total de respostas emitidas no BPP. Valores ao redor de 50\% indicam que nenhum controle diferencial foi exercido pelas luzes. Na Figura 2 estão os índices calculados para cada sessão de cada 
participante. As três curvas da linha de cima são dos três participantes do G1 e as três da linha de baixo são dos três participantes do G2. As mudanças de esquema múltiplo para misto, realizadas para os participantes P7 e

P5
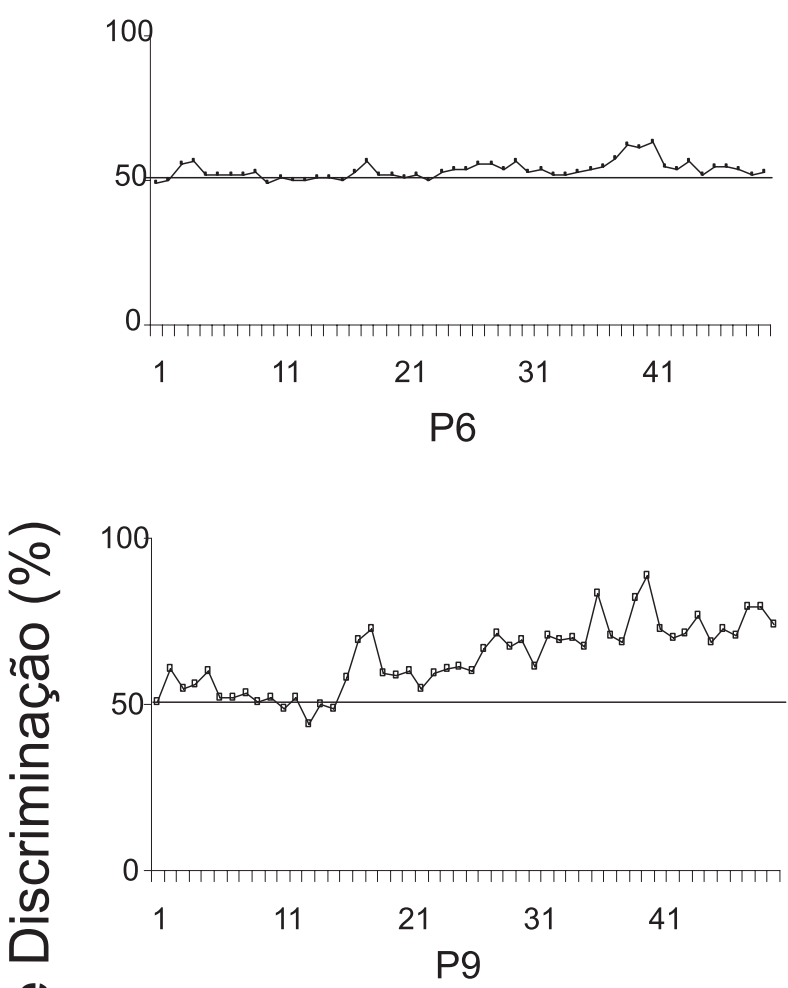

0
0
0.0
.0
.0

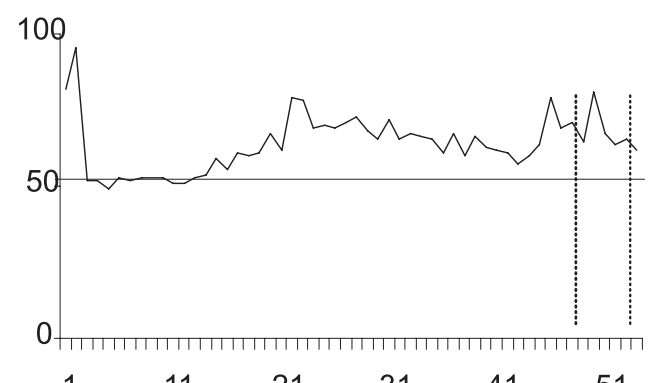

P9, são indicadas pelas linhas pontilhadas nas respectivas curvas. A extinção da resposta de observação que ocorreu para P8 e para P10 também é indicada por linhas pontilhadas nas respectivas curvas.

\section{P7}
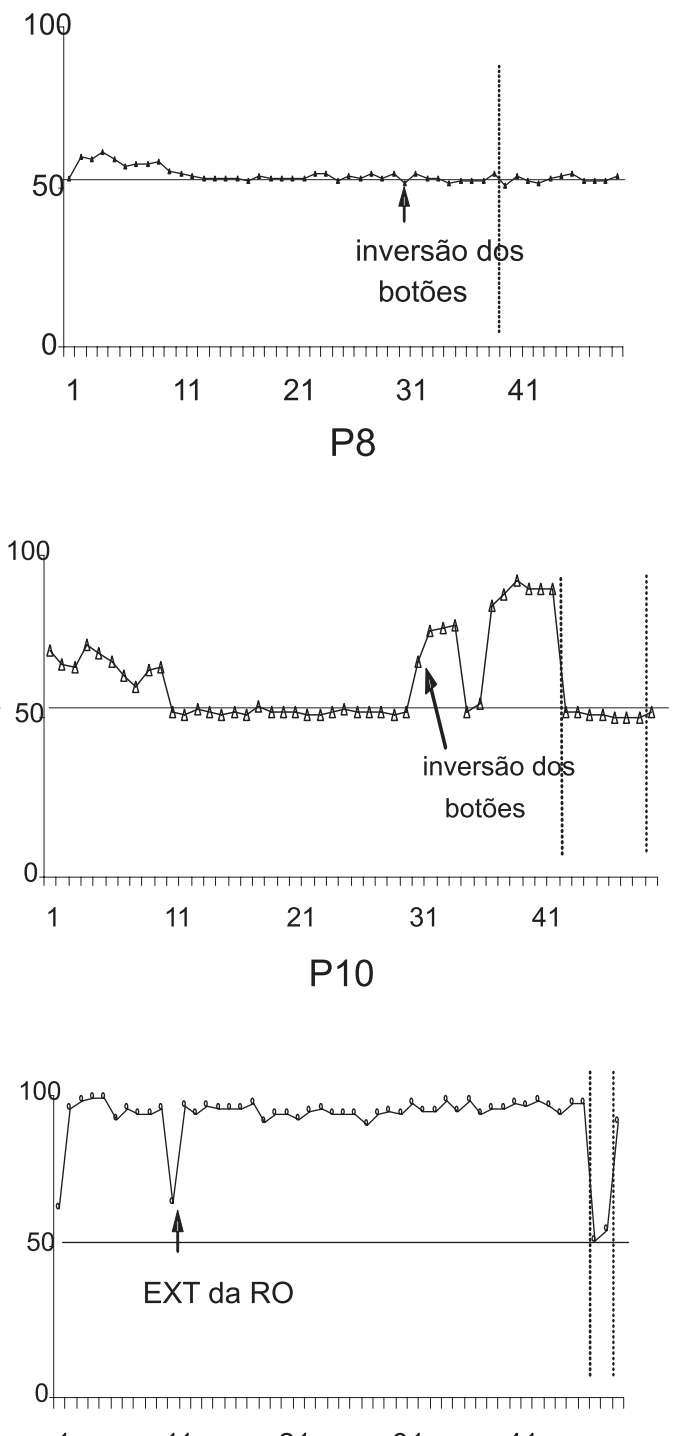

\section{Sessões}

Figura 2. Índice de discriminação das respostas emitidas no botão de produção de pontos dos seis participantes do experimento, ao longo de todas as sessōes. As mudanças de esquema múltiplo para misto, realizadas para os participantes P7 e P9, são indicadas pelas linhas pontilhadas nas respectivas curvas. A extinção da resposta de observação que ocorreu nas contingências programadas para P8 e para P10 também é indicada por linhas pontilhadas nas respectivas curvas. 
Como se pode ver na Figura 2, nenhum participante do G1 atingiu 90\% de índice de discriminação para as respostas no BPP por três sessões consecutivas, critério inicialmente estabelecido para que estes participantes passassem para o esquema mix VI EXT com possibilidade de emissão de respostas de observação. Entre os participantes do $\mathrm{G} 1$, as únicas sessões em que o critério foi atingido foram as duas primeiras de P9 (seu primeiro dia de participação). Durante toda sua participação no experimento, $\mathrm{P} 9$ teve os maiores índices de discriminação do G1. A elevação do botão de produção de pontos, que provavelmente produziu uma elevação no custo de emissão de respostas neste botão - já que o braço dos participantes agora teria que ser sustentado a uma altura mais elevada -, pode ter sido o fator responsável pela melhora no índice de P9 em relação ao dos outros participantes do G1. Porém, não foi verificada a mesma alteração de desempenho em P7, que teve a elevação na sessão 31 e continuou com o mesmo desempenho anterior à elevação.

Em relação aos índices de discriminação para a resposta no BPP dos participantes do G2, pode-se notar uma pequena inclinação positiva na curva de índices discriminativos no desempenho de P6. Porém, como ele já havia realizado suas 50 sessões, não foi possível esperar a estabilização do índice para o encerramento de sua participação. As respostas de P8 só atingiram índices de discriminação acima de 75\% após a inversão da posição dos botões, quando o BPP ficou na posição superior e o BO na posição inferior. Para P8, o critério de $90 \%$ ou mais de respostas no componente de reforçamento foi atingido no quarto dia depois da inversão, ou seja, após seis sessões. As respostas de P10, que já iniciou sua participação com a posição dos dois botões invertida, tive- ram, com exceção da primeira sessão e durante a extinção da resposta de observação, índices superiores ou iguais a $90 \%$ em todas as demais. O desempenho dos participantes P8 e P10 durante a extinção da resposta de observação, na qual pressões no botão de observação eram possíveis, mas não produziam as luzes, foi sensível à mudança na contingência: os índices voltaram a 50\%, ou seja, os participantes distribuíram as respostas no botão de produção de pontos nos dois componentes sem indicação de qualquer controle de estímulos.

É possível uma comparação entre os participantes dos dois grupos aos pares. Cada coluna de curvas da Figura 2 teve os valores dos intervalos dos componentes de reforçamento parecidos (ver Tabela 1 e 2). Os intervalos utilizados nos componentes de reforçamento do esquema múltiplo de P5 são parecidos com os intervalos no componente de reforçamento dos componentes de reforçamento do esquema misto de P6. Porém, os índices de discriminação para as respostas no BPP emitidas por P6 são maiores que os de P5. Este fenômeno também pode ser verificado nos outros dois pares de participantes. Esta diferença se acentua depois da inversão da posição dos botôes - a partir da sessão 31, para P7 e P8, e desde a primeira sessão, para P9 e P10.

A seguir, são apresentadas duas figuras que detalham o desempenho de P8 e P10. Estes dois participantes apresentaram os índices discriminativos mais altos do experimento, indicando controle pelas luzes, condição indispensável para falar-se de comportamento de observação.

A Figura 3 contém, separadamente, curvas com o número total de respostas no $\mathrm{BO}$ e no BPP durante os componentes de reforçamento e de extinção de cada sessão de 
P8. A partir da sessão 11 até a inversão da posição relativa dos botôes (sessão 31), as respostas no BO foram emitidas em baixa freqüência nos dois componentes. Entre as sessões 37 e 42, quando o índice discriminativo de respostas no BPP ficou entre $85 \%$ e $92 \%$, o número de respostas no BPP durante o componente de extinção diminuiu e, simultaneamente, o número de respostas no $\mathrm{BO}$ durante estes componentes aumentou. A inversão da posição entre $\mathrm{BO}$ e BPP pode ter alterado o custo relativo de emissão das respostas nestes botôes, já que o braço do participante precisava ser sustentado em uma posição mais alta durante as pressões no $\mathrm{BPP}$ em relação às pressões no $\mathrm{BO}$. Desta forma, a emissão das respostas de observação pode ter passado a ter um custo relativamente menor que a emissão das respostas de produção de pontos.

Na Figura 4 estão curvas com o número total e duração total, por sessão, das respostas no

botão de observação de P10. Pode-se verificar que, praticamente por todo o experimento, houve uma maior freqüência de respostas no $\mathrm{BO}$ durante o componente de extinção (linha preta pontilhada) do que durante o componente de reforçamento (linha preta contínua). Mesmo nas sessôes em que o número de respostas nos dois componentes foi parecido, a duração total das respostas no $\mathrm{BO}$ durante os componentes de extinção (linha cinza pontilhada) foi superior à duração total das respostas no $\mathrm{BO}$ durante os componentes de reforçamento (linha cinza contínua). Para P8, as durações das respostas de observação não variaram de maneira expressiva durante o experimento.

\section{DISCUSSÃO}

Em relação ao objetivo de replicação dos resultados do experimento de Mulvaney e cols. (1981), os resultados do presente experimento

\section{P8}

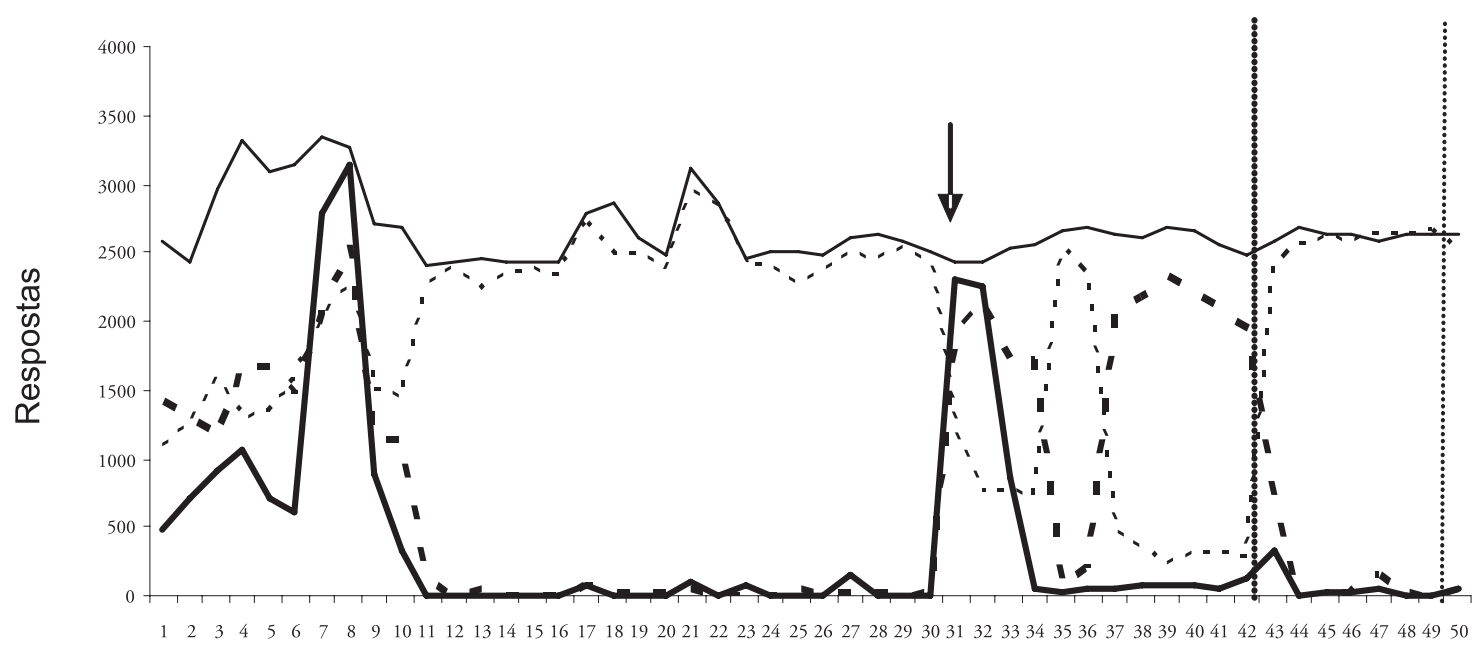

Sessões

Figura 3. Número total de respostas de pressão no BPP (linhas finas) e de pressão no BO (linhas grossas) durante os componentes de reforçamento (linhas contínuas) e de extinção (linhas pontilhadas) de P8, por sessão. A extinção da resposta de observação que ocorreu da Sessão 43 à Sessão 49 é indicada por linhas pontilhadas verticais. A seta indica o momento de inversão das posições de BPP e BO. 


\section{P10}

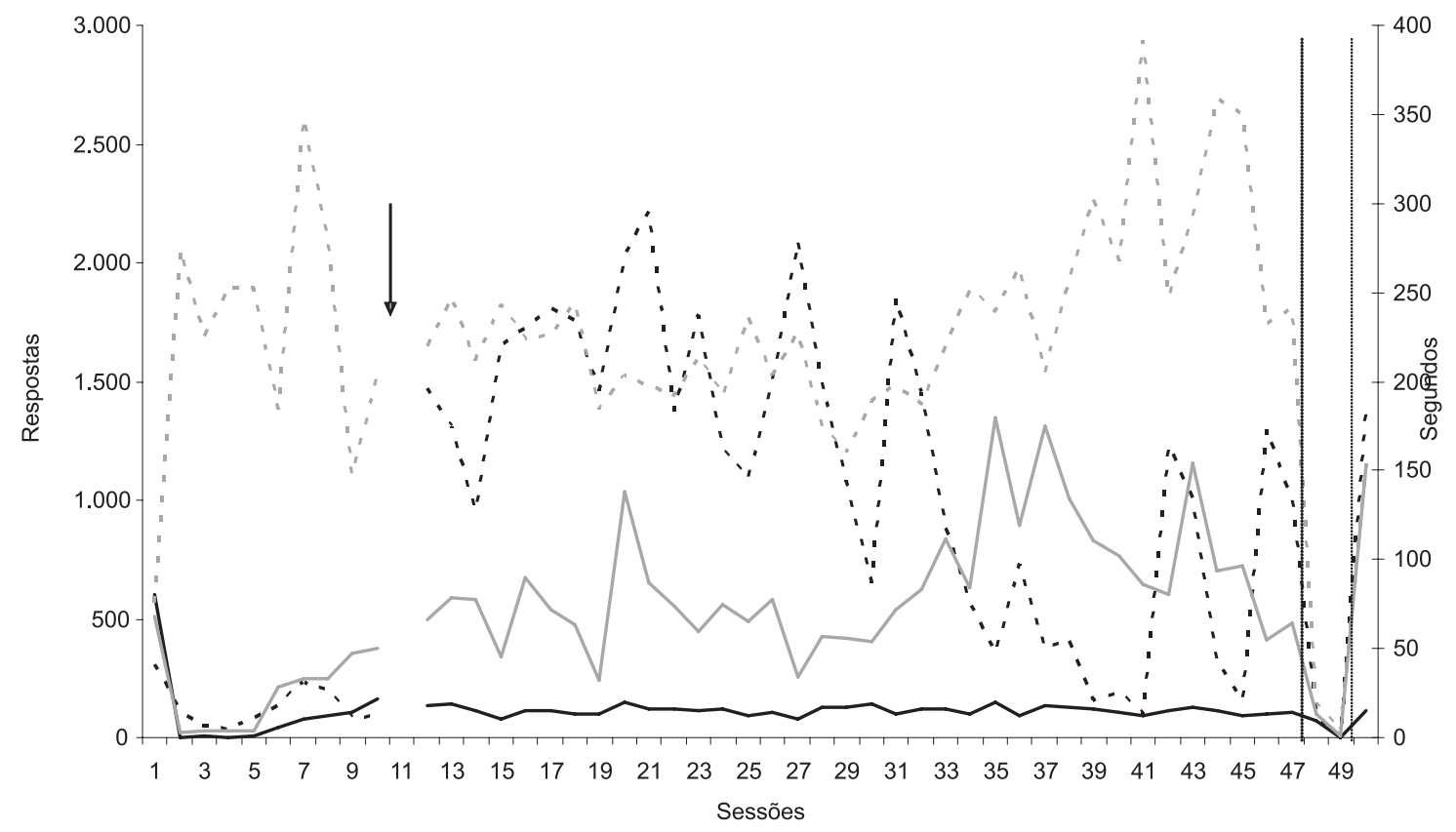

Figura 4. Número total (linhas pretas) e durações (linhas cinzas) das respostas emitidas no BO por P10. As linhas contínuas representam respostas durante os componentes de reforçamento e as linhas pontilhadas representam as respostas durante os componentes de extinção. A extinção da resposta de observação que ocorreu nas sessões 43 e 49 é indicada por linhas pontilhadas verticais. A seta indica a extinção não programada da resposta de observação e perda deste registro.

divergiram em diversos aspectos. A diferença mais importante entre os resultados dos dois experimentos parece ser o fato de que, apesar de situação análoga à de Mulvaney e cols. (1981), neste experimento não houve controle discriminado das respostas de produção pelas diferentes luzes programadas no treino de discriminação. Esse fato aconteceu para todos os participantes do G1. A ausência de controle discriminado pode ser decorrente de diversos fatores como, por exemplo, a idade dos participantes ou a qualidade dos reforçadores utilizados (moedas no procedimento original e pontos trocados por moedas e o som de moedas caindo no presente experimento). Quanto à observação seletiva, só é possível analisá-la em situações de controle pelas luzes, caso de P8 e P10. Para ambos, as respostas de observação foram mais freqüentes durante a vigência dos componentes menos favoráveis para o comportamento de produção (EXT), o que está em acordo com o princípio de observação seletiva proposto por Dinsmoor (1983). Entretanto, a duração das respostas de observação foi igual durante os dois componentes para P8 e foi maior nos componentes menos favoráveis para P10. Esse resultado está em desacordo com o princípio de observação seletiva, que prevê duração mais longa de respostas de observação durante a vigência dos componentes mais favoráveis para o comportamento de produção.

Os índices de discriminação para as respostas de produção de pontos foram maiores para os três participantes que iniciaram o experimento em esquema misto com oportunidade de emissão de respostas de observação do que 
para os três participantes que iniciaram o experimento em esquema múltiplo. Nos dois casos em que o índice de discriminação permaneceu acima de $90 \%$ por três ou mais sessôes, a freqüência ou duração das respostas de observação durante os componentes de extinção foi maior do que durante os componentes de reforçamento. Nestes casos, a inversão de custo de emissão entre as respostas de produção e de observação parece ter sido a condição para a maior freqüência ou duração de respostas de observação que produziam os estímulos relacionados ao componente de extinção. Esta interpretação dos resultados deste experimento corrobora a interpretação de Case e cols. (1985) para seus resultados e os de Perone e Baron (1980). Case e cols. (1985) relacionaram a manutenção do comportamento de observação por estímulo relacionado ao componente menos favorável (maior custo de resposta ou menor taxa de reforçamento) à possibilidade de menor custo de resposta no comportamento de produção. É importante notar, então, que o menor custo de resposta no comportamento de produção pode ser obtido com a possibilidade de ocorrência de um comportamento de observação que tenha um custo de reposta inferior ao custo das respostas do comportamento de produção, talvez independentemente do custo de resposta absoluto do comportamento de produção.

No presente experimento, a inversão de custos entre as respostas de observação e produção pode, ainda, estar relacionada ao estabelecimento do controle de estímulos para os dois participantes do G2 expostos a essa situação. O estabelecimento do controle pelos estímulos discriminativos para as respostas de produção por meio do reforçamento de respostas de observação com custo relativamente menor pode ser uma alternativa para o estabelecimento do controle de estímulos em situações em que este está ausente por alguma razão. Futuros experimentos poderiam ser feitos no sentido de explorar um delineamento ABA do custo relativo das respostas de observação e produção para ampliar generalidade das comparações entre grupos.

\section{REFERÊNCIAS}

Case, D. A., Fantino, E., \& Wixted, J. (1985). Human observing: maintained by negative informative stimuli only if correlated with improvement in response efficiency. Journal of the Experimental Analysis of Behavior, 43, 289-300.

Dinsmoor, J. A. (1983). Observing and conditioned reinforcement. The Behavioral and Brain Sciences, 6, 693-728.

Mulvaney, D. E., Hughes, L. H., Jwaideh, A. R., \& Dinsmoor, J. A. (1981). Differencial production of positive and negative discriminative stimuli by normal and retarded children. Journal of Experimental Children Psychology, 32, 389-400.

Perone, M., \& Baron, A. (1980). Reinforcement of human observing behavior by a stimulus correlated with extinction or increased effort. Journal of the Experimental Analysis of Behavior, 34, 239-261.

Pessôa, C. V. B. B., \& Buffara, A. C. L. (2005). Construção de intervalos variáveis de reforçamento em planilha eletrônica de cálculo. Revista Brasileira de Terapia Comportamentale Cognitiva, 7(1), 133-136.

Wyckoff, L. B. Jr. (1969). The role of observing responses in discrimination learning. Em D. P. Hendry (Ed.), Conditioned Reinforcement (pp. 237260). Homewood, Il: The Dorsey Press.

Submetido em 11 de dezembro de 2007 Aceito em 7 de setembro de 2008 